ISSN electrónico: 2172-9077

https://doi.org/10.14201/fjc201715225227

\title{
TRAYECTORIAS, CICLOS Y MIRADAS DEL CINE ESPAÑOL
}

\section{Spanish Cinema 1982-1996. Trajectories, Cycles and Looks}

Dr. Fernando GONZÁLEZ GARCíA

Profesor titular. Universidad de Salamanca, España.

E-mail: fergogar@usal.es

Fecha de recepción de la reseña: 01/10/2017

Fecha de aceptación definitiva: 18/10/2017

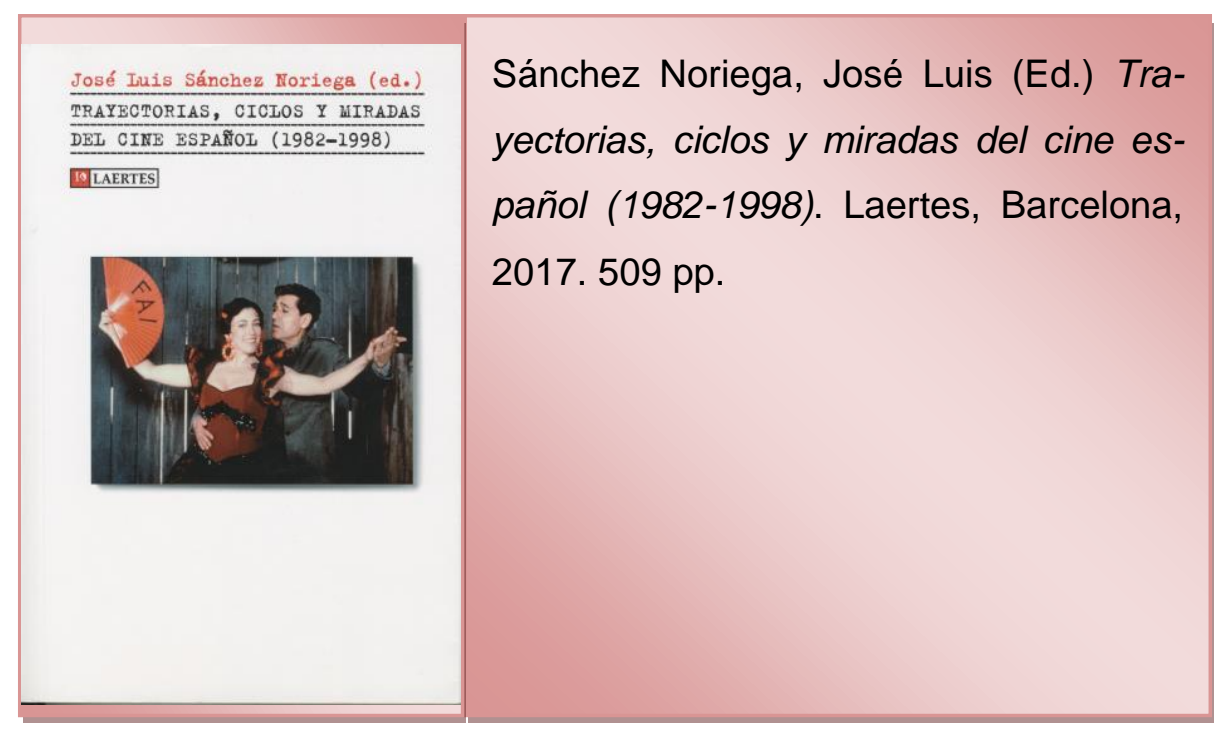

Con la coordinación de este volumen, José Luis Sánchez Noriega continúa la labor emprendida en ediciones anteriores. Si en Filmando el cambio social (Laertes, 2014), el tema de estudio era el cine realizado durante la Transición, Trayectorias, ciclos y miradas del cine español (1982-1998) se centra en el período de consolidación democrática que supusieron los consecutivos gobiernos socialistas. El libro se estructura en tres capítulos introductorios, a los que sigue el análisis de 135 películas: las estrenadas en 1997 y 1998, ya durante el gobierno del Partido Popular, se justifican por estar gestadas en el período 
que se analiza. Los dos primeros capítulos funcionan como marcos sucesivos y concéntricos: Juan Carlos Pereira Castañares resume la evolución política durante este período, junto con las transformaciones económicas, las sociales -mayores niveles de tolerancia, justicia e igualdad-, y los retos que supone la integración europea, también en lo relativo a la nueva situación geoestratégica y geopolítica de España. Juan Antonio Pérez Millán y Ernesto Pérez Morán cierran el campo sobre la política cultural, en concreto la que atañe a la cinematografía, cuyas claves, protección, promoción y conservación, se irán modificando -sobre todo las dos primeras-, en función de distintos factores. Unos son políti$\cos -\mathrm{y}$ el capítulo permite ver disensiones en el seno del propio PSOE-; otros vienen determinados por la integración en Europa, que hace más complejas las políticas proteccionistas; otros, en fin, tienen que ver con los intereses divergentes de los actores sectoriales. En el tercer capítulo, José Luis Sánchez Noriega enfoca con más detalle cuestiones claves que atañen a las relaciones de la cinematografía con la sociedad del período. En principio, la crisis del sector, derivada del descenso de espectadores en sala, con la consiguiente reestructuración -cierres de cines, por un lado, y apertura de complejos multisala, por otro-; la concentración de la distribución en un número menor de empresas, vinculadas en buena parte a intereses norteamericanos, afecta de manera directa a los estrenos de películas españolas. También la política de subvenciones es responsable de la caída de la oferta y del aumento de los costes de producción. Esta política, que en un principio favoreció la aparición de la figura del director productor, en detrimento de la industria, permite el regreso de autores que habían debutado hacia los años sesenta y que habían quedado relativamente relegados durante los años de la Transición. Presta atención Sánchez Noriega a la aparición de nuevas generaciones de realizadores y la desigual respuesta de los espectadores a sus propuestas, así como al surgimiento de un número cada vez mayor de directoras. Un siguiente bloque está dedicado a los temas recurrentes durante estos años. En primer lugar, llama la atención la cantidad de películas que hacen cuentas con el pasado reciente de España, en particular el de la guerra civil y la posguerra. Preocupaciones o intereses en el diálogo que el cine mantiene con la realidad social son también la familia, las relaciones afectivas y sexuales, cuyo tratamiento se aleja del de la etapa anterior, haciéndose menos reivindicativo o festivo -el autor escribe en cursiva más normalizado - y en ocasiones más explícito, la conflictividad y la marginación a través de historias con protagonistas jóvenes, así como, más recientemente, problemas como la inmigración y el desempleo. En lo que atañe a los géneros, se pone el foco en especial sobre la evolución del documental hacia la no ficción, la importancia de las transposiciones de textos literarios y su evolución, y la renovación de la comedia. Esta panorámica termina llamando la atención sobre la importancia de filmotecas y publicaciones especializadas en la generación de una cultura cinematográfica en crecimiento.

El criterio cronológico es esencial en este libro, no solo en estos capítulos introductorios, como veremos. Se trata de que el lector perciba estos dieciséis años no como un período monolítico, sino como plagado de cambios: un proceso con encabalgamientos generacionales, intereses sectoriales contrapuestos, transformaciones políticas, geopolíticas y sociales de profundo calado, durante el que incluso lo que podría aparecer como un punto de referencia o de perspectiva, es decir la voluntad del Estado en considerar lo cinematográfico como parte de una política cultural, está también sujeto a cambios y tensiones.

La segunda y más amplia parte del volumen, el análisis de una selección de 135 películas, está realizada por Francisco M. Benavent, Bénédicte Brénard, Óscar Curieses, Virginia Guarinos, Miguel Huerta Floriano, Gonzalo M. Pavés Borges, Ernesto Pérez Morán, José Antonio Planes Pedreño, Marie-Soledad Rodríguez, Pedro Sangro Colón, y José Luis Sánchez Noriega. La organización parte del mismo criterio cronológico: se abre con Cuerpo a cuerpo (Paulino Viota, 1982), y se cierra con Torrente, el brazo tonto de la ley (Santiago Segura, 1998), de manera que se puede ir siguiendo año a año el proceso comentado más arriba. La reseña de cada película -forzosamente breve-, sigue un modelo, aplicado por cada firmante con una cierta flexibilidad: ficha técnico-artística, resumen argumental, análisis, resultado en taquilla y recepción crítica. Aunque pueda haber diferencias en lo que se acentúa -la dimensión autorial, la capacidad de la obra para dialogar con el espectador, la representación de la 
mujer-, en general las reseñas combinan la perspectiva textual con la social, atendiendo, en consonancia con los capítulos introductorios, a la posición de cada obra en un contexto dinámico y cambiante.

Aunque hay cuestiones en las que no se profundiza, como la capacidad exportadora del cine español, la producción autonómica, con la consiguiente cuestión lingüística en algunos casos, la formación de un número cada vez mayor de cineastas en el campo del cortometraje, o lo que tiene que ver con los actores y actrices -desde la posibilidad de hablar de un pequeño star system, de figuras y papeles recurrentes, hasta de cambios en los modos de actuación, y de recambio generacional también en ese sector-, Trayectorias, ciclos y miradas del cine español (1982-1998) representa una importante síntesis del período.

\section{FONSECA, JOVRNAL OF COMMVNICATION}

